\title{
Association of endothelin genetic variants and hospitalized infection complications in end-stage renal disease (ESRD) patients
}

\author{
Chih-Chin Kao ${ }^{1,2,3}$, Shih-Ying Cheng ${ }^{4,5}$, Yu-Jia Wang ${ }^{6}$, Shu-Chen Chien ${ }^{4,5,7}$, Yu-Wen Hsu' ${ }^{8}$, Mei-Yi Wü3,9, \\ Hsing-Fang Lu' ${ }^{5}$, Sean Nam ${ }^{5}$, Tao Sun ${ }^{10}$, Mai-Szu Wu ${ }^{1,3,9^{*}+}$ and Wei-Chiao Chang $5,11,12,13^{*+}$
}

\begin{abstract}
Background: Infection is the second most common cause of mortality for patients with end-stage renal disease (ESRD), accompanying with immune dysfunction. Endothelin (EDN) is known to be related to inflammation; however, it is unknown whether genetic variants of the EDN gene family are associated with increased risk of hospitalized infection events.

Methods: Nineteen tagging single-nucleotide polymorphisms (tSNPs) of the EDN gene family were selected for genotyping a cohort of 190 ESRD patients. Patient demographics were recorded, the subtypes of infection events were identified, and association analysis between the EDN genetic variants and hospitalized infection events was performed.

Results: In this study, 106 patients were hospitalized for infection events. The leading events were pneumonia, bacteremia, and cellulitis. The minor allele of rs260741, rs197173, and rs926632 SNPs of EDN3 were found to be associated with reduced risk of hospitalized bacteremia events.

Conclusions: The minor allele of rs260741, rs197173, and rs926632 in EDN3 were associated with reduced risk of hospitalized bacteremia events in ESRD patients.
\end{abstract}

Keywords: Endothelin, End stage renal disease, Infection, Renal failure

\section{Background}

Infection is known as a common cause of morbidity and mortality in patients with end-stage renal disease (ESRD), accounting for $20 \%$ of total deaths in these patients [1]. More than half of patients hospitalized for infection events developed an unfavorable outcome, including prolonged hospitalization, intensive care unit (ICU) stay, or even death $[2,3]$. Impaired innate and adaptive immunity are associated with increased risk of infection in patients with renal failure [4]. A handful of cytokines was dysregulated in ESRD patients; for example, the production of interleukin

\footnotetext{
* Correspondence: maiszuwu@gmail.com; wcc@tmu.edu.tw

${ }^{\dagger}$ Mai-Szu Wu and Wei-Chiao Chang contributed equally to this work.

${ }^{1}$ Graduate Institute of Clinical Medicine, College of Medicine, Taipei Medical University, Taipei, Taiwan

${ }^{5}$ Department of Clinical Pharmacy, School of Pharmacy, College of Pharmacy, Taipei Medical University, Taipei, Taiwan

Full list of author information is available at the end of the article
}

(IL)-1, tumor necrosis factor (TNF)- $\alpha$, and IL-6 was increased, whereas the bioavailability of IL-2 was reduced [5].

Genetic variants of immune-related genes have been shown to reflect risk of infection. Ferwerda et al. reported that the genetic variants of Toll-like receptor 4, which underlies the differential production of cytokines may affect the immune system, which in turn influenced the susceptibility of infection events and the risk of gram-negative bacterial infection [6]. Moreover, another study demonstrated that an $I L-9$ variant may influence the susceptibility of respiratory syncytial virus infection [7].

Endothelin-1 (ET-1) is the major isoform of the endothelin $(E D N)$ family and is a potent vasoconstrictor. It is associated with proinflammatory cytokine production, fibrosis, and angiogenesis [8]. The release of lipopolysaccharide from bacteria impairs the integrity of the endothelial cell, resulting in endothelial cell injury and cytokine release [9]. The plasma

(c) The Author(s). 2019 Open Access This article is distributed under the terms of the Creative Commons Attribution 4.0 International License (http://creativecommons.org/licenses/by/4.0/), which permits unrestricted use, distribution, and reproduction in any medium, provided you give appropriate credit to the original author(s) and the source, provide a link to the Creative Commons license, and indicate if changes were made. The Creative Commons Public Domain Dedication waiver (http://creativecommons.org/publicdomain/zero/1.0/) applies to the data made available in this article, unless otherwise stated. 
ET-1 level is increased during sepsis and is correlated with the severity of sepsis [10]. ET-1 is known to increase reactive oxygen species (ROS) production, and associates with activation of nuclear factor-kappaB and inflammatory cytokines such as TNF- $\alpha$, IL-1, and IL-6 [11]. In addition, Lin et al. reported that ET-1 is able to increase cyclooxygenase-2 expression and prostaglandin E2 release [12]. These findings suggest that ET-1 is involved in the inflammatory reactions and the severity of sepsis. Regarding ET-3, Sato et al. demonstrated that low level of ET-3 reduces inflammatory responses [13]. However, it is still unclear whether $E D N$ genetic variants are associated with hospitalized infection events in ESRD patients. In this study, genetic association study was applied to investigate the correlations between EDN genetic variants and the hospitalized infection events in ESRD patients.

\section{Methods}

\section{Study population}

Patients who received dialysis for more than 3 months at Taipei Medical University Hospital between September 2013 and June 2014 were enrolled. Demographic and laboratory data of these patients was shown in Table 1 . The erythropoietin resistance index (ERI) was determined to characterize patients' response to erythropoietin. ERI was calculated by dividing the weekly body-weight-adjusted epoetin dose by the hemoglobin concentration. $\mathrm{Kt} / \mathrm{V}$ was used to measure dialysis adequacy. Outpatient and discharge medical records were used to determine the cause of ESRD. We prospectively followed up with the patients who were hospitalized for infection events. This study was approved by the Institutional Review Board of Taipei Medical University (Approval No. 201309026). A written informed consent form was obtained from all patients.

Table 1 Baseline characteristics of study patients stratified by infection events

\begin{tabular}{|c|c|c|c|}
\hline & Infection events $(n=106)$ & No infection events $(n=84)$ & $P$ value \\
\hline Sex: Male, n (\%) & $58(54.7 \%)$ & $45(53.6 \%)$ & 0.875 \\
\hline Age (years) & $66 \pm 13$ & $62 \pm 13$ & 0.020 \\
\hline Dialysis vintage (years) & $4.6 \pm 4.0$ & $4.9 \pm 6.1$ & 0.705 \\
\hline Current smoking (\%) & $16(15.1 \%)$ & $9(10.7 \%)$ & 0.375 \\
\hline Diabetes, n (\%) & $55(51.9 \%)$ & $35(41.7 \%)$ & 0.161 \\
\hline ERI (unit/week/kg/Hb) & $8.2 \pm 6.9$ & $8.6 \pm 4.1$ & 0.670 \\
\hline Hemoglobin (g/dL) & $10.7 \pm 1.3$ & $10.8 \pm 1.0$ & 0.764 \\
\hline Albumin (g/dL) & $3.9 \pm 0.4$ & $4.0 \pm 0.4$ & 0.033 \\
\hline Ferritin (mg/dL) & $510 \pm 664$ & $390 \pm 431$ & 0.153 \\
\hline Iron (mg/dL) & $66 \pm 24$ & $68 \pm 31$ & 0.610 \\
\hline $\mathrm{TIBC}(\mathrm{mg} / \mathrm{dL})$ & $231 \pm 40$ & $247 \pm 54$ & 0.024 \\
\hline Serum iPTH (pg/mL) & $280 \pm 349$ & $390 \pm 377$ & 0.050 \\
\hline $\mathrm{Kt} / \mathrm{N}$ & $1.52 \pm 0.30$ & $1.48 \pm 0.28$ & 0.459 \\
\hline Cause of ESRD, n (\%) & & & 0.253 \\
\hline Hypertension & $21(19.8 \%)$ & $16(19.0 \%)$ & \\
\hline Diabetes & $54(50.9 \%)$ & $33(39.3 \%)$ & \\
\hline GN & $18(17.0 \%)$ & $20(23.8 \%)$ & \\
\hline $\mathrm{CHF}$ & $5(4.7 \%)$ & $3(3.6 \%)$ & \\
\hline Others & $8(7.5 \%)$ & $12(14.3 \%)$ & \\
\hline \multicolumn{4}{|l|}{ Infection events } \\
\hline Bacteremia & $24(22.6 \%)$ & & \\
\hline Pneumonia & 38 (35.8\%) & & \\
\hline UTI & $10(9.4 \%)$ & & \\
\hline Cellulitis & $22(20.8 \%)$ & & \\
\hline Peritonitis & 21 (19.8\%) & & \\
\hline$|A|$ & $10(9.4 \%)$ & & \\
\hline
\end{tabular}

The $P$ values of $<0.05$ are shown in bold Abbreviations: CHF congestive heart failure, ERI erythropoietin resistance index, GN glomerulonephritis, IAl intra-abdominal infection, iPTH parathyroid hormone, $T I B C$ total iron binding capacity, UTI urinary tract infection 


\section{Infection events}

We defined hospitalized "infection events" as bacteremia, pneumonia, cellulitis, urinary tract infection (UTI), peritonitis, and intra-abdominal infection (IAI). Bacteremia was confirmed by a positive blood culture result, and contamination was excluded by an infection specialist. Pneumonia was defined as the presence of clinical respiratory symptoms and the findings of increased infiltration on chest radiography. Cellulitis was determined as inflammation of the skin and subcutaneous tissues. UTI was defined as the presence of clinical symptoms and the detection of a pathogen in the urine. Peritonitis was diagnosed through clinical symptom examination and peritoneal fluid analysis. IAI was confirmed by the finding of intramural inflammation of the gastrointestinal (GI) tract without anatomic disruption. These diagnoses were ascertained by physicians and recorded in the discharge medical records.

\section{Genotyping}

Patients' blood samples were collected, and their genomic DNA was extracted. We selected 5 tagging single-nucleotide polymorphisms (tSNPs) of EDN1 (i.e., rs5370, rs2070699, rs2248580, rs4714384, and rs3087459; Fig. 1a), 4 tSNPs of EDN2 (i.e., rs2759257, rs11210278, rs11572340, and rs11572377; Fig. 1b), and 10 tSNPs of EDN3 (i.e., rs742650, rs260740, rs260741, rs6064764, rs197173, rs197174, rs882345, rs926632, rs3026575, and rs11570352; Fig. 1c). The SNPs were selected by using $r^{2}>0.8$ for linkage disequilibrium (LD) and $\mathrm{MAF}>10 \%$ in a Beijing Han Chinese population as the setting of the Haploview software 4.1 (Broad Institute, Cambridge, MA, USA). The SNPs that are located in exon or untranslated regions (UTR) are defined as high priority targets to be included in selection. The LD map of target genes and SNPs selection were shown based on $\mathrm{r}^{2}$ and $\mathrm{D}^{\prime}$ in Additional file 1: Figures S1-S3. We performed genotyping using a TaqMan Allelic Discrimination Assay (Applied Biosystems, Foster City, CA). A polymerase chain reaction was performed on an ABI StepOnePlus Thermal Cycler (Applied Biosystems, Foster City, CA). The fluorescence from different probes was detected and analyzed using System SDS software version 2.2.2 (Applied Biosystems, Foster City, CA).

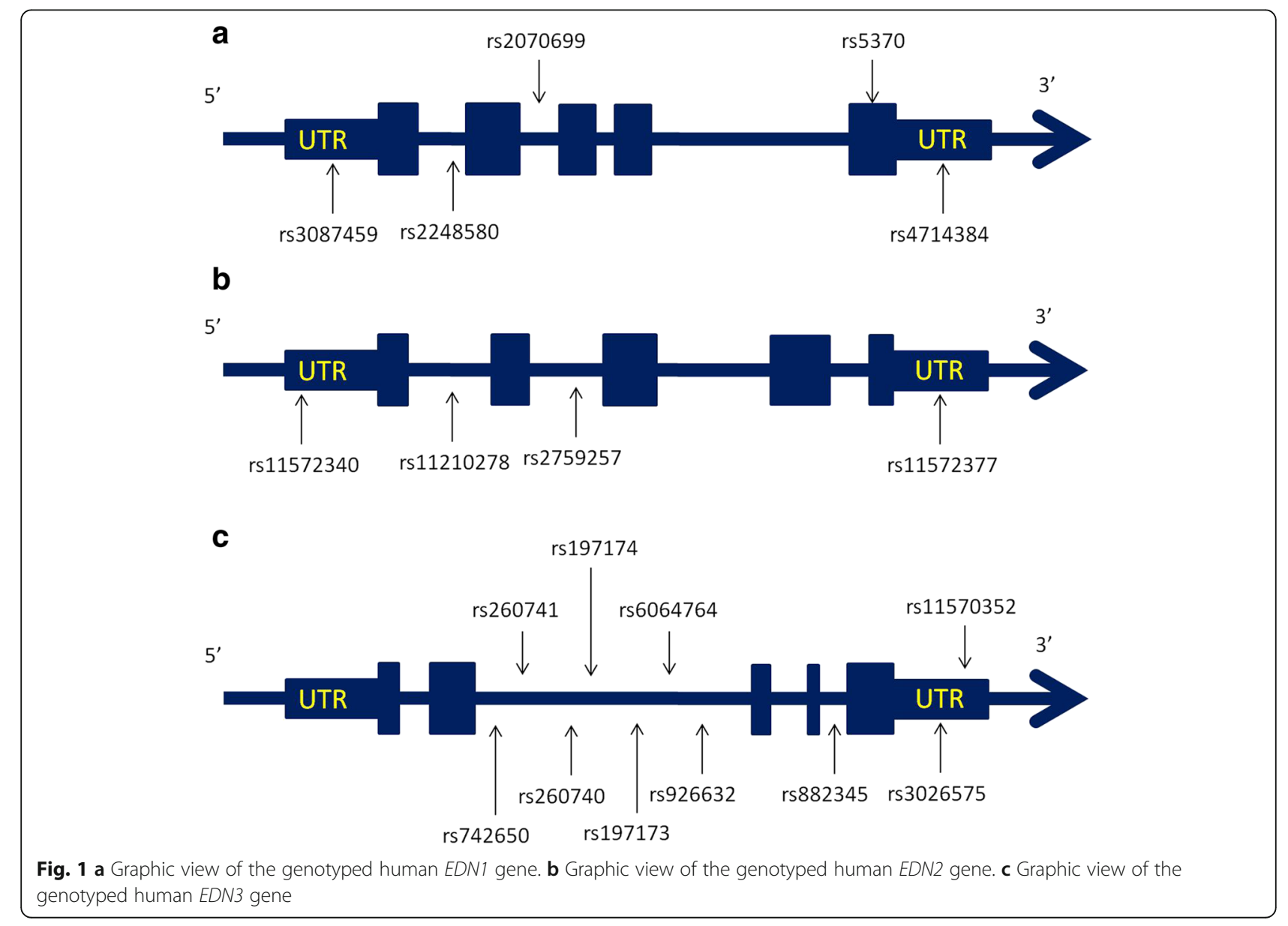


Table 2 Analysis of association between EDN3 single-nucleotide polymorphisms (SNPs) and hospitalized infection events

\begin{tabular}{|c|c|c|c|c|c|c|c|c|c|}
\hline & Genotype & $\begin{array}{l}\text { Infection } \\
(n=106)\end{array}$ & (\%) & $\begin{array}{l}\text { Without } \\
\text { infection } \\
(n=84)\end{array}$ & (\%) & $\begin{array}{l}\text { Genotype model } \\
P \text { value }\end{array}$ & $\begin{array}{l}\text { Dominant model } \\
P \text { value }\end{array}$ & $\begin{array}{l}\text { Recessive model } \\
P \text { value }\end{array}$ & $\begin{array}{l}\text { Allelic model } \\
P \text { value }\end{array}$ \\
\hline \multirow[t]{3}{*}{ rs742650 } & $\pi$ & 1 & 1.2 & 1 & 1.7 & 0.4215 & 0.8156 & 0.2224 & 0.9896 \\
\hline & $C T$ & 18 & 20.9 & 9 & 15.5 & & & & \\
\hline & CC & 67 & 77.9 & 48 & 82.8 & & & & \\
\hline \multirow[t]{3}{*}{ rs260740 } & GG & 0 & 0.0 & 1 & 1.7 & 0.3925 & 0.8894 & 0.1864 & 0.9252 \\
\hline & GT & 29 & 30.9 & 14 & 23.3 & & & & \\
\hline & $\pi$ & 65 & 69.1 & 45 & 75.0 & & & & \\
\hline \multirow[t]{3}{*}{ rs260741 } & $\mathrm{AA}$ & 6 & 7.1 & 6 & 11.1 & 0.5823 & 0.4068 & 0.3609 & 0.3127 \\
\hline & $A G$ & 30 & 35.3 & 20 & 37.0 & & & & \\
\hline & GG & 49 & 57.6 & 28 & 51.9 & & & & \\
\hline \multirow[t]{3}{*}{ rs6064764 } & CC & 2 & 2.1 & 1 & 1.3 & 0.1387 & 0.0568 & 0.9998 & 0.0938 \\
\hline & $C T$ & 21 & 22.1 & 7 & 9.3 & & & & \\
\hline & $\pi$ & 72 & 75.8 & 67 & 89.3 & & & & \\
\hline \multirow[t]{3}{*}{ rs197173 } & $\pi$ & 6 & 6.7 & 9 & 13.8 & 0.5902 & 0.9957 & 0.3368 & 0.6674 \\
\hline & GT & 31 & 34.8 & 20 & 30.8 & & & & \\
\hline & GG & 52 & 58.4 & 36 & 55.4 & & & & \\
\hline \multirow[t]{3}{*}{ rs197174 } & GG & 2 & 2.1 & 3 & 4.9 & 0.2504 & 0.2100 & 0.1494 & 0.1253 \\
\hline & GA & 17 & 18.1 & 11 & 18.0 & & & & \\
\hline & $\mathrm{AA}$ & 75 & 79.8 & 47 & 77.0 & & & & \\
\hline \multirow[t]{3}{*}{ rs882345 } & GG & 4 & 4.3 & 0 & 0.0 & 0.0168 & 0.2688 & 0.0350 & 0.7671 \\
\hline & GA & 9 & 9.7 & 12 & 18.5 & & & & \\
\hline & $\mathrm{AA}$ & 80 & 86.0 & 53 & 81.5 & & & & \\
\hline \multirow[t]{3}{*}{ rs926632 } & CC & 3 & 3.2 & 2 & 2.9 & 0.0096 & 0.0095 & 0.6393 & 0.0534 \\
\hline & $C T$ & 9 & 9.5 & 18 & 25.7 & & & & \\
\hline & $\pi$ & 83 & 87.4 & 50 & 71.4 & & & & \\
\hline \multirow[t]{3}{*}{ rs3026575 } & $\mathrm{AA}$ & 0 & 0.0 & 1 & 1.5 & 0.0754 & 0.2642 & 0.0269 & 0.1212 \\
\hline & $A G$ & 6 & 6.4 & 5 & 7.7 & & & & \\
\hline & GG & 88 & 93.6 & 59 & 90.8 & & & & \\
\hline \multirow[t]{3}{*}{ rs11570352 } & $\pi$ & 3 & 2.9 & 5 & 6.0 & 0.3515 & 0.7034 & 0.2324 & 0.4364 \\
\hline & $\mathrm{TC}$ & 4 & 3.8 & 1 & 1.2 & & & & \\
\hline & CC & 97 & 93.3 & 78 & 92.9 & & & & \\
\hline
\end{tabular}

The $P$ value was adjusted for age, sex, diabetes, hemoglobin, albumin, and the cause of ESRD. The $P$ values of $<0.05$ are shown in bold

\section{Statistical analysis}

Statistical analyses were conducted using R 3.2.0 (http:// www.r-project.org/; http://cran.r-project.org/). The chisquared test and Student's $t$ test were used to compare demographic characteristics between study (infection events) and control (no infection events) group. $P<0.05$ was considered statistically significant. We used a multivariable logistic regression model to analyze the association of the EDN SNPs with hospitalized infection events. Four genetic models (genotype, dominant, recessive, allelic model) were evaluated in this study. These models were adjusted to reduce the confounding effects, including age, sex, diabetes, hemoglobin, albumin, and the cause of ESRD. LD was analyzed, and haplotype blocks were drawn using the default setting of the Haploview software 4.1 (Broad Institute, Cambridge, MA, USA).

\section{Results}

\section{Clinical characteristics of patients}

A total of 190 ESRD patients were enrolled at Taipei Medical University Hospital. Patient's clinical characteristics were summarized in Table 1 . More than half of patients (56\%) developed hospitalized infection events during the observation period. The laboratory results haven't displayed a significant difference between 
Table 3 Analysis of association between EDN3 single-nucleotide polymorphisms (SNPs) and hospitalized bacteremia events

\begin{tabular}{|c|c|c|c|c|c|c|c|c|c|}
\hline & Genotype & $\begin{array}{l}\text { Bacteremia } \\
(n=24)\end{array}$ & $(\%)$ & $\begin{array}{l}\text { Without } \\
\text { bacteremia } \\
(n=84)\end{array}$ & (\%) & $\begin{array}{l}\text { Genotype model } \\
P \text { value }\end{array}$ & $\begin{array}{l}\text { Dominant model } \\
P \text { value }\end{array}$ & $\begin{array}{l}\text { Recessive model } \\
P \text { value }\end{array}$ & $\begin{array}{l}\text { Allelic model } \\
P \text { value }\end{array}$ \\
\hline \multirow[t]{3}{*}{ rs742650 } & $\pi$ & 0 & 0 & 1 & 1.7 & 0.4983 & 0.3770 & 0.5773 & 0.4870 \\
\hline & $C T$ & 6 & 30.0 & 9 & 15.5 & & & & \\
\hline & CC & 14 & 70.0 & 48 & 82.8 & & & & \\
\hline \multirow[t]{3}{*}{ rs 260740} & GG & 0 & 0.0 & 1 & 1.7 & 0.5886 & 0.9802 & 0.3185 & 0.8360 \\
\hline & GT & 7 & 33.3 & 14 & 23.3 & & & & \\
\hline & $\pi$ & 14 & 66.7 & 45 & 75.0 & & & & \\
\hline \multirow[t]{3}{*}{ rs260741 } & $\mathrm{AA}$ & 0 & 0.0 & 6 & 11.1 & 0.0203 & 0.0165 & 0.0350 & 0.0077 \\
\hline & $A G$ & 4 & 21.1 & 20 & 37.0 & & & & \\
\hline & GG & 15 & 78.9 & 28 & 51.9 & & & & \\
\hline \multirow[t]{3}{*}{ rs6064764 } & CC & 1 & 4.5 & 1 & 1.3 & 0.0905 & 0.0286 & 0.5282 & 0.0447 \\
\hline & $C T$ & 6 & 27.3 & 7 & 9.3 & & & & \\
\hline & $\pi$ & 15 & 68.2 & 67 & 89.3 & & & & \\
\hline \multirow[t]{3}{*}{ rs197173 } & $\Pi$ & 0 & 0.0 & 9 & 13.8 & 0.0447 & 0.0393 & 0.0465 & 0.0188 \\
\hline & GT & 4 & 19.0 & 20 & 30.8 & & & & \\
\hline & GG & 17 & 81.0 & 36 & 55.4 & & & & \\
\hline \multirow[t]{3}{*}{ rs197174 } & GG & 0 & 0.0 & 3 & 4.9 & 0.3176 & 0.3178 & 0.1659 & 0.2094 \\
\hline & GA & 5 & 25.0 & 11 & 18.0 & & & & \\
\hline & $A A$ & 15 & 75.0 & 47 & 77.0 & & & & \\
\hline \multirow[t]{3}{*}{ rs882345 } & GG & 0 & 0.0 & 0 & 0.0 & 0.1100 & NA & NA & NA \\
\hline & GA & 1 & 4.8 & 12 & 18.5 & & & & \\
\hline & $A A$ & 20 & 95.2 & 53 & 81.5 & & & & \\
\hline \multirow[t]{3}{*}{ rs926632 } & CC & 0 & 0.0 & 2 & 2.9 & 0.0395 & 0.0123 & 0.3256 & 0.0112 \\
\hline & $C T$ & 1 & 4.8 & 18 & 25.7 & & & & \\
\hline & $\pi$ & 20 & 95.2 & 50 & 71.4 & & & & \\
\hline \multirow[t]{3}{*}{ rs3026575 } & $A A$ & 0 & 0.0 & 1 & 1.5 & 0.8634 & 0.5878 & 0.9999 & 0.5879 \\
\hline & $A G$ & 1 & 4.8 & 5 & 7.7 & & & & \\
\hline & GG & 20 & 95.2 & 59 & 90.8 & & & & \\
\hline \multirow[t]{3}{*}{ rs11570352 } & $\pi$ & 1 & 4.2 & 5 & 6.0 & 0.6086 & 0.4834 & 0.6859 & 0.5661 \\
\hline & $\mathrm{TC}$ & 0 & 0.0 & 1 & 1.2 & & & & \\
\hline & CC & 23 & 95.8 & 78 & 92.9 & & & & \\
\hline
\end{tabular}

The $P$ value was adjusted for age, sex, diabetes, hemoglobin, albumin, and the cause of ESRD. The $P$ values of $<0.05$ are shown in bold

infection and non-infection groups, except for the albumin level and total iron binding capacity (TIBC). The cause of ESRD was found to be similar for both groups; diabetes mellitus was the main cause. The main hospitalized infection events were pneumonia (35.8\%), followed by bacteremia $(22.6 \%)$, cellulitis $(20.8 \%)$, peritonitis (19.8\%), UTI (9.4\%), and IAI (9.4\%). Patient's demographics were stratified by bacteremia events, and six bacteria species, which are Staphylococcus aureus, Acinetobacter baumannii, Escherichia coli, Enterococcus faecium, Klebsiella pneumonia, and Staphylococcus hemolyticus, were under investigation (Additional file 1: Table S1). The inflammatory markers include procalcitonin (PCT) and c-reactive protein (CRP). The mean level of PCT was $3.6 \pm 3.2 \mathrm{ng} / \mathrm{mL}$, and CRP was $8.5 \pm 9.2 \mathrm{mg} / \mathrm{dL}$.

\section{Associations between EDN genetic variants and hospitalized infection events}

The association analysis was performed for detecting the relationship of $E D N$ genetic variants and hospitalized infection events. We haven't observed a significant association between the frequencies of both EDN1 and EDN2 genotypes and clinical outcomes (Additional file 1: Table S2 and S3), but the rs882345, rs926632 and rs3026575 


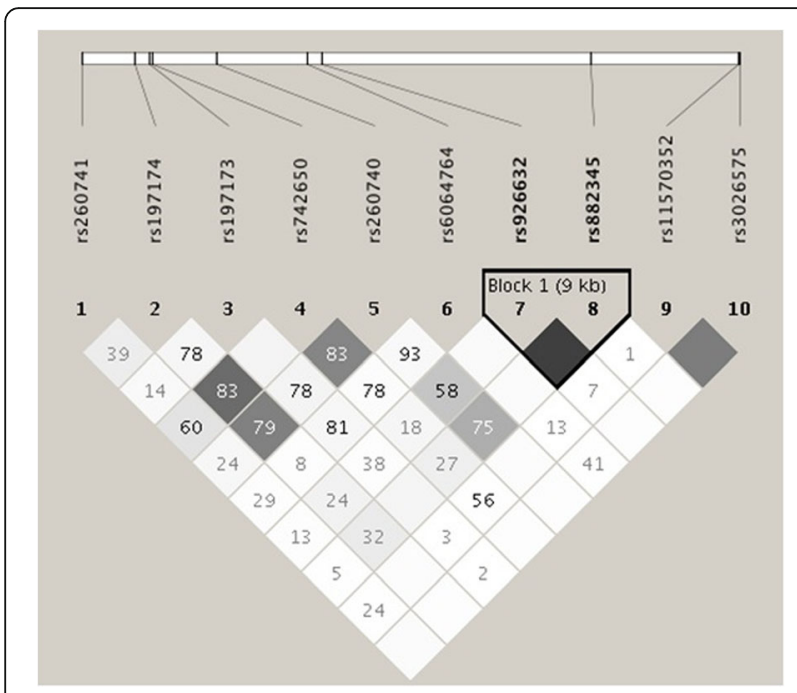

Fig. 2 EDN3 gene linkage disequilibrium (LD) and haplotype block structure in ESRD patients. The number on the cell is the LOD score of $r^{2}$

of EDN3 showed a modest association with hospitalized infection events (Table 2).

\section{Associations between EDN genetic variants and hospitalized bacteremia events}

The rs260741, rs6064764, rs197173, and rs926632 of EDN3 genotypes showed a significant association with hospitalized bacteremia events (Table 3). Patients carrying the minor allele of EDN3 rs260741 (AA/AG vs. GG), rs197173 (TT/TG vs. GG), and rs926632 (CC/CT vs. TT) had a lower risk of hospitalized bacteremia events (genotype model, dominant model, and allelic model $P$ value $<0.05)$. The minor allele of rs6064764 (CC/CT vs. TT) was associated with increased risk of bacteremia according to the dominant model and allelic model $P$ values (Table 3). No association of EDN1 or EDN2 SNPs with hospitalized bacteremia events were detected (Additional file 1: Table S4 and S5).

\section{Haplotypes analysis of EDN3 with infection and bacteremia events}

Next, we further validated the effects of haplotypes of $E D N 3$ gene by pairwise linkage disequilibrium (LD)

Table 4 Haplotype frequencies of EDN3 gene rs926632/ rs882345 among patients with hospitalized infection events or not

\begin{tabular}{lllll}
\hline rs926632/rs882345 & Case & Control & OR $(95 \% \mathrm{Cl})$ & $P$ value \\
\hline T/A & $91 \%$ & $84 \%$ & 1 & Ref \\
C/A & NA & $6 \%$ & - & - \\
C/G & $9 \%$ & $9 \%$ & $0.93(0.46-1.90)$ & 0.8131 \\
\hline
\end{tabular}

Haplotype frequency less than $1 \%$ was excluded Abbreviation: $O R$ odds ratio
Table 5 Haplotype frequencies of EDN3 gene rs926632/ rs882345 among patients with hospitalized bacteremia events or not

\begin{tabular}{lllll}
\hline rs926632/rs882345 & Case & Control & OR $(95 \%$ Cl $)$ & $P$ value \\
\hline T/A & $97 \%$ & $87 \%$ & 1 & Ref \\
C/A & NA & $3 \%$ & - & - \\
C/G & $3 \%$ & $10 \%$ & $0.29(0.04-2.02)$ & 0.1791 \\
\hline
\end{tabular}

Haplotype frequency less than $1 \%$ was excluded Abbreviation: $O R$ odds ratio

(Fig. 2). The haplotype frequency of EDN3 rs926632/ rs882345 variants among patients with hospitalized infection and bacteremia events were shown in Tables 4 and 5 . The EDN3 haplotype had no significant association with the risk of infection or bacteremia events. To test the possible functional roles of the polymorphisms in EDN3, we queried expression quantitative trait loci (eQTL) of EDN3 via Genotype-Tissue Expression (GTEx) database in different types of tissues [14]. Of note, the low expression level of EDN3 was found in immune cells (Additional file 1: Figure S4). In addition, we analyzed the SNPs to understand the functional roles through using HaploReg V4.1. Interestingly, results indicated that the non-coding SNP rs260741 and rs6064764 of EDN3 were potentially related to the regulation of $\mathrm{T}$ cells activation by epigenetic modifications [15].

\section{Discussion}

Dialysis patients are exposed to high risk of infection, and related mortality $[16,17]$. Ishigami et al. reported that a low estimated glomerular filtration rate and high albuminuria were associated with increased risk of hospitalization for infection, including bloodstream infections, pneumonia, UTI, and cellulitis [18]. Among these infections, bacteremia was the most critical and responsible for three-quarters of infection-related mortality [19]. The risk factors for infection in dialysis patients include age, immunosuppressive therapy, poor hygiene, and low performance status [17, 20-22]. Age, albumin level, and category of infection have been shown to associate with poor outcomes [23]. Old age and lower albumin level were the risk factors for infection events. Indeed, both innate and adaptive immunity are known to change with age, which may result in a persistent low-grade inflammation and tissue damage [24]. Furthermore, T-cell repertoire (TCR) complexity was revealed to predict the EPO responsiveness. Thus, TCR repertoire diversity may indicate the immune responses to infection [25]. Malnutrition, inflammation, and atherosclerosis syndrome, characterized by patients with renal failure, are predictive of poor outcomes [26]. 
Importantly, malnutrition has also been reported to associate with chronic inflammation, followed by increased risk of infection [27].

Correa et al. reported that EDN signaling pathway is involved in the pathogenesis of mycobacteria tuberculosis infection, and that EDN receptor $\mathrm{A}$ or $\mathrm{B}$ signaling is critical for the host responses to the infection [28]. Wilson et al. indicated the functional roles of $E D N$ genes in intestinal hypoperfusion during bacteremia [29]. Additionally, the precursor peptide ET-1 of EDN1 gene is correlated with the severity of pneumonia, ICU admission, and mortality [30]. Also, ET-1 has been shown to stimulate ROS production [9] and correlate with the risk of inflammatory diseases such as atherosclerosis. Our previous study showed genetic variants of EDN1 gene are associated with an increased risk of hospitalization for a cardiovascular event [31]. Pittet et al. demonstrated that the serum level of ET-1 was strongly correlated with reduced cardiac output in sepsis patients [32]. In this study, we found the correlation between EDN genetic variants and hospitalized infection events..

A previous study on EDN3 and EDN receptor type B (EDNRB) knockout mouse model showed that $E D N 3$ and $E D N R B$ were associated with severe enterocolitis [33]. The ET-3 peptide of EDN3 gene was reported to evoke an attenuated inflammation by inducing the EDN B2 receptor and nitric oxide production [13]. Another study also proposed that ET-3 reduces platelet-activating factor (PAF)-induced inflammation by directly binding to PAF [34]. Interestingly, the Human Protein Atlas showed that ET-3 is highly expressed in the GI tract and endocrine tissues [35]. During the development of enteric nervous system, ET-3 and its receptor, EDNRB, orchestrate the signaling cascades for enteric ganglion formation [3638]. The enteric nervous system, composing of neurons and glial cells, have been shown to interact with the outer (microbiota) and inner environments (immune cells) [39]; the enteric microbiota is known to interact with the immune system [40]. These studies indicated that ET-3 may affect the inflammation process through the modification of enteric nervous system and interaction with the microbiota. The results provided indirect evidence for supporting our findings in this study.

This study has limitations. First, our small sample size may affect the statistical power in the analysis. Second, the gene expression and protein level of $E D N$ were not measured from patients' samples. Further validation studies are needed in order to evaluate the associations of genetic variants with gene/protein expression. Third, a replication study should be conducted in the second population.

\section{Conclusions}

The minor allele of rs260741, rs197173, and rs926632 in EDN3 was associated with a reduced risk of hospitalized bacteremia events in patients with end-stage renal disease (ESRD).

\section{Additional files}

\begin{abstract}
Additional file 1: Figure S1. Linkage disequilibrium (LD) map of EDN1 gene SNPs shown (a) based on R-squared $\left(r^{2}\right)(b)$ based on D-prime ( $\left.D^{\prime}\right)$. Figure S2. Linkage disequilibrium (LD) map of EDN2 gene SNPs shown (a) based on R-squared $\left(r^{2}\right)$ (b) based on D-prime ( $\left.D^{\prime}\right)$. Figure S3. Linkage disequilibrium (LD) map of EDN3 gene SNPS shown (a) based on Rsquared $\left(r^{2}\right)(b)$ based on D-prime $\left(D^{\prime}\right)$. Figure S4. EDN3 gene expression across different tissues. Table S1. Baseline characteristics of study patients stratified by bacteremia events. Table S2. Analysis of association between EDN1 single-nucleotide polymorphisms (SNPS) and hospitalized infection events. Table S3. Analysis of association between EDN2 singlenucleotide polymorphisms (SNPs) and hospitalized infection events.

Table S4. Analysis of association between EDN1 single-nucleotide polymorphisms (SNPs) and hospitalized bacteremia events. Table S5. Analysis of association between EDN2 single-nucleotide polymorphisms (SNPs) and hospitalized bacteremia events. (DOCX $196 \mathrm{~kb}$ )
\end{abstract}

\section{Abbreviations}

EDN: Endothelin; ERI: Erythropoietin resistance index; ESRD: End-stage renal disease; ET-1: Endothelin-1; GTEx: Genotype-Tissue Expression; Kt/N: Adequacy of dialysis

\section{Acknowledgements}

None declared.

\section{Funding}

The study was supported by the funding and grants from the Ministry of Health and Welfare (MOHW104-TDU-B-212-113001), Ministry of Science and Technology (MOST107-2314-B-038-019-MY3), and Taipei Medical University Hospital (103TMUH-NE-04). These funding was responsible for laboratory supplies, personnel expense and staff technical fees.

\section{Availability of data and materials}

All data related to this article are shown in the manuscript or are available upon request from the corresponding authors.

\section{Authors' contributions}

C-CK contributed to the study concept and design; data research; analysis and interpretation of data; drafting of the manuscript. S-YC performed molecular genetic studies and researched the data. Y-JW contributed to the results interpretation, concept discussion and manuscript writing. S-CC contributed to the study concept and design and data research. Y-WH analyzed and interpreted the data. M-YW: study concept and design. H-FL: concept discussion, and researched the data. SN contributed to the manuscript writing and concept discussion. TS contributed to concept discussion. M-SW contributed to the study concept and design and approved the final version of the manuscript to be published. W-CC contributed to the study concept and experimental design, data analysis and manuscript writing.

\section{Ethics approval and consent to participate}

This study was approved by the Institutional Review Board of Taipei Medical University (Approval no. 201309026), and written informed consent was obtained from all patients.

Consent for publication

Not applicable.

Competing interests

The authors declare that they have no competing interests. 


\section{Publisher's Note}

Springer Nature remains neutral with regard to jurisdictional claims in published maps and institutional affiliations.

\section{Author details \\ ${ }^{1}$ Graduate Institute of Clinical Medicine, College of Medicine, Taipei Medical University, Taipei, Taiwan. Division of Nephrology, Department of Internal Medicine, Taipei Medical University Hospital, Taipei, Taiwan. ${ }^{3}$ Division of Nephrology, Department of Internal Medicine, School of Medicine, College of Medicine, Taipei Medical University, Taipei, Taiwan. ${ }^{4}$ Department of Pharmacy, Taipei Medical University Hospital, Taipei, Taiwan. ${ }^{5}$ Department of Clinical Pharmacy, School of Pharmacy, College of Pharmacy, Taipei Medical University, Taipei, Taiwan. ${ }^{6}$ Ph.D. Program for Neural Regenerative Medicine, College of Medical Science and Technology, Taipei Medical University, Taipei, Taiwan. ${ }^{7}$ Clinical Research Center, Taipei Medical University Hospital, Taipei, Taiwan. ${ }^{8}$ Ph.D. Program for Translational Medicine, College of Medical Science and Technology, Academia Sinica, Taipei Medical University, Taipei, Taiwan. ${ }^{9}$ Division of Nephrology, Department of Internal Medicine, Shuang Ho Hospital, Taipei Medical University, New Taipei City, Taiwan. ${ }^{10}$ Department of Surgery, University of Chicago, Chicago, IL, USA. ${ }^{11}$ Department of Pharmacy, Wan Fang Hospital, Taipei Medical University, Taipei, Taiwan. ${ }^{12}$ Master Program for Clinical Pharmacogenomics and Pharmacoproteomics, School of Pharmacy, Taipei Medical University, Taipei 110, Taiwan. ${ }^{13}$ Department of Medical Research, Shuang Ho Hospital, Taipei Medical University, New Taipei City, Taiwan.}

Received: 28 March 2018 Accepted: 23 April 2019

Published online: 05 June 2019

\section{References}

1. Kato S, Chmielewski M, Honda H, Pecoits-Filho R, Matsuo S, Yuzawa Y, et al. Aspects of immune dysfunction in end-stage renal disease. Clin J Am Soc Nephrol. 2008:3(5):1526-33.

2. Allon M, Radeva M, Bailey J, Beddhu S, Butterly D, Coyne DW, et al. The spectrum of infection-related morbidity in hospitalized haemodialysis patients. Nephrol Dial Transplant. 2005;20(6):1180-6.

3. Slinin Y, Foley RN, Collins AJ. Clinical epidemiology of pneumonia in hemodialysis patients: the USRDS waves 1, 3, and 4 study. Kidney Int. 2006; 70(6):1135-41.

4. Eleftheriadis T, Liakopoulos V, Leivaditis K, Antoniadi G, Stefanidis I. Infections in hemodialysis: a concise review - part 1: bacteremia and respiratory infections. Hippokratia. 2011;15(1):12-7.

5. Descamps-Latscha B. The immune system in end-stage renal disease. Curr Opin Nephrol Hypertens. 1993;2(6):883-91.

6. Ferwerda B, McCall MB, Alonso S, Giamarellos-Bourboulis EJ, Mouktaroudi M, Izagirre N, et al. TLR4 polymorphisms, infectious diseases, and evolutionary pressure during migration of modern humans. Proc Natl Acad Sci U S A 2007:104(42):16645-50

7. Schuurhof $A$, Bont $L$, Siezen $C L$, Hodemaekers $H$, van Houwelingen $H C$, Kimman TG, et al. Interleukin-9 polymorphism in infants with respiratory syncytial virus infection: an opposite effect in boys and girls. Pediatr Pulmonol. 2010:45(6):608-13.

8. Elisa T, Antonio P, Giuseppe P, Alessandro B, Giuseppe A, Federico C, et al. Endothelin receptors expressed by immune cells are involved in modulation of inflammation and in fibrosis: relevance to the pathogenesis of systemic sclerosis. J Immunol Res. 2015;2015:147616.

9. Kowalczyk A, Kleniewska P, Kolodziejczyk M, Skibska B, Goraca A. The role of endothelin-1 and endothelin receptor antagonists in inflammatory response and sepsis. Arch Immunol Ther Exp. 2015;63(1):41-52.

10. Pan C, Wang J, Liu W, Liu L, Jing L, Yang Y, et al. Low tidal volume protects pulmonary vasomotor function from "second-hit" injury in acute lung injury rats. Respir Res. 2012;13:77

11. Yeager ME, Belchenko DD, Nguyen CM, Colvin KL, Ivy DD, Stenmark KR. Endothelin-1, the unfolded protein response, and persistent inflammation: role of pulmonary artery smooth muscle cells. Am J Respir Cell Mol Biol. 2012;46(1):14-22.

12. Lin $\mathrm{CC}$, Hsieh $\mathrm{HL}$, Shih $\mathrm{RH}$, Chi PL, Cheng SE, Yang CM. Up-regulation of COX-2/PGE2 by endothelin-1 via MAPK-dependent NF-kappaB pathway in mouse brain microvascular endothelial cells. Cell Commun Signal. 2013; 11(1):8.
13. Sato A, Ebina K. Endothelin-3 at low concentrations attenuates inflammatory responses via the endothelin B2 receptor. Inf Res. 2013;62(4): 417-24.

14. Lonsdale J, Thomas J, Salvatore M, Phillips R, Lo E, Shad S, et al. The Genotype-Tissue Expression (GTEx) project. Nat Genet. 2013;45(6):580-5.

15. Kundaje A, Meuleman W, Ernst J, Bilenky M, Yen A, Heravi-Moussavi A, et al. Integrative analysis of 111 reference human epigenomes. Nature. 2015; 518(7539):317-30.

16. Nassar GM, Ayus JC. Infectious complications of the hemodialysis access. Kidney Int. 2001;60(1):1-13.

17. Vandecasteele SJ, Boelaert JR, De Vriese AS. Staphylococcus aureus infections in hemodialysis: what a nephrologist should know. Clin J Am Soc Nephrol. 2009:4(8):1388-400.

18. Ishigami J, Grams ME, Chang AR, Carrero JJ, Coresh J, Matsushita KCKD. Risk for hospitalization with infection: the atherosclerosis risk in communities (ARIC) study. Am J Kidney Dis. 2017;69(6):752-61.

19. Bloembergen WE, Port FK. Epidemiological perspective on infections in chronic dialysis patients. Adv Ren Replace Ther. 1996;3(3):201-7.

20. Kaplowitz LG, Comstock JA, Landwehr DM, Dalton HP, Mayhall CG. A prospective study of infections in hemodialysis patients: patient hygiene and other risk factors for infection. Infect Control Hosp Epidemiol. 1988: 9(12):534-41.

21. Teehan GS, Bahdouch D, Ruthazer R, Balakrishnan VS, Snydman DR, Jaber BL Iron storage indices: novel predictors of bacteremia in hemodialysis patients initiating intravenous iron therapy. Clin Infect Dis. 2004;38(8):1090-4.

22. Hoen B, Paul-Dauphin A, Hestin D, Kessler M. EPIBACDIAL: a multicenter prospective study of risk factors for bacteremia in chronic hemodialysis patients. J Am Soc Nephrol. 1998:9(5):869-76.

23. Allon M, Depner TA, Radeva M, Bailey J, Beddhu S, Butterly D, et al. Impact of dialysis dose and membrane on infection-related hospitalization and death: results of the HEMO Study. J Am Soc Nephrol. 2003;14(7):1863-70.

24. Shaw AC, Joshi S, Greenwood H, Panda A, Lord JM. Aging of the innate immune system. Curr Opin Immunol. 2010;22(4):507-13.

25. Wong HS, Chang CM, Kao CC, Hsu YW, Liu X, Chang WC, et al. V-J combinations of T-cell receptor predict responses to erythropoietin in endstage renal disease patients. J Biomed Sci. 2017;24(1):43.

26. Tonbul HZ, Demir M, Altintepe L, Guney I, Yeter E, Turk S, et al. Malnutritioninflammation-atherosclerosis (MIA) syndrome components in hemodialysis and peritoneal dialysis patients. Ren Fail. 2006;28(4):287-94.

27. Pawlaczyk K, Oko A, Lindholm B, Czekalski S. Malnutrition -- inflammation -atherosclerosis (MIA syndrome) in patients with renal failure. Pol Merkur Lekarski. 2003;15(88):334-41 discussion 41-3.

28. Correa AF, Bailao AM, Bastos IM, Orme IM, Soares CM, Kipnis A, et al. The endothelin system has a significant role in the pathogenesis and progression of mycobacterium tuberculosis infection. Infect Immun. 2014;82(12):5154-65.

29. Wilson MA, Steeb GD, Garrison RN. Endothelins mediate intestinal hypoperfusion during bacteremia. J Surg Res. 1993;55(2):168-75.

30. Schuetz P, Stolz D, Mueller B, Morgenthaler NG, Struck J, Mueller C, et al. Endothelin-1 precursor peptides correlate with severity of disease and outcome in patients with community acquired pneumonia. BMC Infect Dis. 2008;8:22.

31. Kao CC, Cheng SY, Wu MY, Chien SC, Lu HF, Hsu YW, et al. Associations of genetic variants of endothelin with cardiovascular complications in patients with renal failure. BMC Nephrol. 2017:18(1):291.

32. Pittet JF, Morel DR, Hemsen A, Gunning K, Lacroix JS, Suter PM, et al. Elevated plasma endothelin-1 concentrations are associated with the severity of illness in patients with sepsis. Ann Surg. 1991;213(3):261-4.

33. Frykman PK, Cheng Z, Wang X, Dhall D. Enterocolitis causes profound lymphoid depletion in endothelin receptor B- and endothelin 3-null mouse models of Hirschsprung-associated enterocolitis. Eur J Immunol. 2015;45(3):807-17.

34. Sato A, Ebina K. Common mechanism in endothelin-3 and PAF receptor function for anti-inflammatory responses. Eur J Pharmacol. 2013;718(1-3):30-3.

35. Ponten F, Jirstrom K, Uhlen M. The Human Protein Atlas--a tool for pathology. J Pathol. 2008;216(4):387-93.

36. Barlow A, de Graaff E, Pachnis $V$. Enteric nervous system progenitors are coordinately controlled by the $\mathrm{G}$ protein-coupled receptor EDNRB and the receptor tyrosine kinase RET. Neuron. 2003:40(5):905-16.

37. Kabouridis PS, Pachnis V. Emerging roles of gut microbiota and the immune system in the development of the enteric nervous system. J Clin Invest. 2015;125(3):956-64.

38. Hosoda K, Hammer RE, Richardson JA, Baynash AG, Cheung JC, Giaid A, et al. Targeted and natural (piebald-lethal) mutations of endothelin-B receptor 
gene produce megacolon associated with spotted coat color in mice. Cell. 1994;79(7):1267-76.

39. Obata $Y$, Pachnis $V$. The effect of microbiota and the immune system on the development and organization of the Enteric Nervous System.

Gastroenterology. 2016;151(5):836-44.

40. Belkaid $Y$, Hand TW. Role of the microbiota in immunity and inflammation. Cell. 2014;157(1):121-41.

Ready to submit your research? Choose BMC and benefit from:

- fast, convenient online submission

- thorough peer review by experienced researchers in your field

- rapid publication on acceptance

- support for research data, including large and complex data types

- gold Open Access which fosters wider collaboration and increased citations

- maximum visibility for your research: over $100 \mathrm{M}$ website views per year

At $\mathrm{BMC}$, research is always in progress.

Learn more biomedcentral.com/submissions 